Journal of Informatics and Computer Science Vol. 4 No. 2 Oktober 2018

Universitas Ubudiyah Indonesia

e-ISSN : 2615-5346

\title{
SISTEM INFORMASI GEOGRAFIS \\ PEMETAAN LETAK AKUIFER PROVINSI ACEH
}

\section{GEOGRAPHICAL INFORMATION SYSTEM OF ACEH \\ PROVINCE ACCOUNTING MAPPING}

Muhammad Bayu Wibawa ${ }^{1}$, Dian Sofyana ${ }^{2}$

Prodi Teknik Informatika Fakultas Ilmu Komputer, Universitas Ubudiyah Indonesia

Jl. Alue Naga Tibang. Kec. Syiah Kuala, Banda Aceh, Indonesia ${ }^{1 \text { dan } 2}$

Email: mbayuw@uui.ac.id ${ }^{1}$, sofyanaina@gmail.com²

\begin{abstract}
Abstrak - Sumur bor merupakan salah satu jenis sumur buatan yang dibuat dengan bantuan alat bor, untuk mencapai kedalaman sumur yang cukup sehingga akan bertemu dengan sumber air tanah yang melimpah. Air tanah tersebut tersimpan dalam lapisan akuifer. Saat ini sulit untuk menemukan daerah yang banyak mengandung air, dikarenakan belum adanya peta potensi air tanah yang memungkinkan mengetahui lokasi daerah yang mengandung banyak air, mengingat untuk masing- masing daerah memiliki keadaan hidrogeologi yang berbeda-beda. Oleh karena itu dilakukan pengamatan atau survei di Kabupaten/Kota yang ada di Aceh. Tujuan penelitian ini merancang aplikasi pemetaan letak akuifer di Aceh berbasis web yang mampu memberikan informasi dan akses kepada petugas maupun pengguna untuk mengetahui letak akuifer terhadap kondisi hidrogeologi pada Provinsi Aceh melalui peta interaktif. Hasil dari penelitian dapat menampilkan data lokasi sumur bor pada Provinsi Aceh. User umum dapat dengan cepat mengetahui daerah mana saja yang mengandung banyak air jika dilihat dari keadaan geologi pada suatu daerah. Untuk pengembangannya dapat menambahkan fungsi web service sehingga memudahkan user dalam penggunaanya dan informasi yang disediakan lebih banyak.
\end{abstract}

\section{Kata Kunci : Web, GIS, Pemetaan, Sumur Bor, Akuifer, data spasial, Google Maps API, JavaScript, PHP}

Abstract - Borehole is one of artificial wells constructed with the assistance of a drill tool. It is deployed to reach the certain depth of well, so abundant water sources can be found. The waters are stored in the aquifer layers. Currently, due to the lack of potential water source maps, it is difficult to find areas that contain plentiful waters. The maps are possible to determine to find those areas since each of them has different states of hydrogeology. In each regency or city in Aceh, therefore, did observations or surveys. Those were carried out to design the web-based mapping application against aquifer locations. It was able to provide information and access of the areas to the officers or users. This interactive mapping application was based on the hydrogeology condition in Aceh province. The search result could display the location data of boreholes within all areas in the province. In addition, geologically, the application allowed public users to discover the areas containing a lot of water in no time. During its development, the application also added web service to offer more information and help users for the operation.

Keywords : Web, GIS, mapping, borehole, aquifer, spatial data, Google Maps API, JavaScript, PHP 
Journal of Informatics and Computer Science Vol. 4 No. 2 Oktober 2018

Universitas Ubudiyah Indonesia

e-ISSN : 2615-5346

\section{PENDAHULUAN Latar Belakang}

Provinsi Aceh memiliki daerah yang sebagian besar merupakan wilayah perbukitan yang memiliki cukup banyak potensi energi air yang bisa dikembangkan sebagai sumber energi primer, salah satunya adalah sumur bor. Sumur bor merupakan salah satu jenis sumur buatan yang dibuat dengan bantuan alat bor, untuk mencapai kedalaman sumur yang cukup sehingga akan bertemu dengan sumber air tanah yang melimpah. Air tanah tersebut tersimpan dalam lapisan yang disebut akuifer. Akuifer adalah lapisan bawah tanah yang mengandung air dan dapat mengalirkan air.

Saat ini sulit untuk menemukan daerah yang banyak mengandung air, dikarenakan belum adanya peta potensi air tanah yang memungkinkan mengetahui lokasi daerah yang mengandung banyak air, mengingat untuk masing-masing daerah memiliki keadaan hidrogeologi yang berbeda-beda. Maka dari itu untuk mengetahui daerah mana saja yang mengandung banyak air maka diperlukan Peta Cekungan Air Tanah (CAT) yang digunakan sebagai acuan dalam menentukan segala kegiatan pengelolaan air tanah mulai dari pengambilan kebijakan, penyusunan strategi dan rencana pengelolaan, serta pelaksanaan, pemantauan dan evaluasi terhadap pelaksanaan konservasi, pendayagunaan dan pengendalian daya rusak air tanah. Pendukung untuk mendapatkan air tanah yang baik dibutuhkan informasi berupa data yang akurat dan akuntable sehingga petugas atau pengguna dapat mengetahui letak akuifer terhadap kondisi hidrogeologi pada Provinsi Aceh. Untuk mendukung penelitian yang dilakukan terhadap pengembangan aplikasi ini, juga dibutuhkan data dan fakta yang terdapat dilapangan. Oleh karena itu dilakukan pengamatan atau survei yang dilakukan di Kabupaten dan Kota yang ada di Aceh.
Berdasarkan uraian diatas maka dibutuhkan sebuah Sistem Informasi Geografis berbasis web yang dapat membantu dalam menyelesaikan masalah di lapangan, sehingga informasi yang diberikan akan lebih cepat, efektif dan efisien serta data yang dihasilkan lebih akurat dan tidak terjadi redudansi data. Sistem informasi dapat diakses melalui browser pada komputer maupun smartphone. Sistem informasi ini menggunakan metode kuantitaatif, dimana data yang didapatkan merupakan data mentah dari Dinas Pertambangan dan Energi Aceh dan kemudian diolah dengan berbagai macam tools, seperti $P H P$ sebagai bahasa pemrograman yang digunakan untuk membangun aplikasi, MySQL sebagai database server, ArcGIS sebagai pengolah data spasial yang akan menghasilkan data dalam bentuk Keyhole Markup Language (KML) dan Google Maps API sebagai framework yang akan menampilkan peta pada web browser.

Sistem Informasi Geografis ini nantinya dapat memudahkan pendataan sumur bor dan dapat dilihat bagaimana keadaan geologi pada suatu daerah yang dilakukan oleh Dinas Pertambangan dan Energi Aceh diseluruh Provinsi Aceh melalui peta interaktif.

\section{Identifikasi Masalah}

Berdasarkan latar belakang masalah di atas, maka dapat diidentifikasikan beberapa masalah yaitu :

1. Belum adanya sarana yang memberikan informasi letak akuifer terhadap kondisi hidrogeologi pada Provinsi Aceh.

2. Petugas kesulitan dalam memperoleh informasi mengenai letak akuifer terhadap kondisi hidrogeologi pada Provinsi Aceh.

3. Pengarsipan data-data mengenai sumur 
Journal of Informatics and Computer Science Vol. 4 No. 2 Oktober 2018

Universitas Ubudiyah Indonesia

e-ISSN : 2615-5346

bor masih dalam bentuk berkas-berkas manual yang disimpan dalam lemari.

Menurut penelitian yang telah dilakukan sebelumnya, Ofvelia Thrisha Gijoh (2017) membahas tentang sistem Penelitian yang menggunakan metode geolistrik resistivitas konfigurasi dipol-dipol bertujuan untuk menembus kedalam tanah yang dilakukan di Masjid Kampus Universitas Sam Ratulangi dan sekitarnya. Penelitian dilakukan pada 5 lintasan dengan menggunakan spasi elektroda yang berbeda- beda. Data setiap lintasan diolah menggunakan perangkat lunak RES2DINV.

Selanjutnya penelitian dari Wahyu Adi Yuliyanto tahun 2016 yaitu Desain Pengembangan Aplikasi Pelayanan Air Bersih Desa Sarirejo Kecamatan Guntur Kabupaten Demak Berbasis GIS Desktop. Melalui desain pengembangan aplikasi ini dihasilkan sebuah aplikasi berbasis GIS Desktop yang mudah dalam rangka mengoptimalkan pengelolaan air bersih desa (ABDES). Kegunaan aplikasi ini antara lain memberikan informasi geospasial data pelanggan, pengelola dan infrastruktur ABDES beserta manajemen databasenya. Aplikasi ini berbasis desktop sehingga hanya dapat dijalankan di komputer atau laptop.

Terakhir penelitian dari Juita Harianja tahun 2014 yaitu Aplikasi Sistem Informasi Geografi (SIG) untuk Pemetaan Akuifer di Kota Denpasar. Data yang ditampilkan berisi informasi mengenai akuifer di Kota Denpasar dalam bentuk peta, dengan ditunjukkan kondisi karakteristik akuifernya.

Karakteristik akuifer yang dimaksud adalah kedalaman muka air tanah, tebal akuifer, kemiringan muka air tanah, nilai koefisien permeabilitas, porositas, kualitas air, susunan akuifer. Salah satu untuk menganalisis dan mengkajinya adalah dengan menggunakan Sistem Informasi Geografi (SIG).

Dari ketiga penelitian diatas terdapat beberapa kesamaan bahan yaitu mengetahui letak akuifer dan dihasilkan dalam bentuk peta. Akan tetapi perbedaannya adalah peneliti menggunakan sistem informasi geografis berbasis web yang ditampilkan dalam bentuk peta interaktif untuk mengetahui letak akuifer terhadap kondisi hidrogeolginya. Sistem informasi geografis berbasis web ini menggunakan framework PHP untuk membuat sistem informasi lebih dinamis, aman dan untuk menampilkan data dari database.

\section{TINJAUAN PUSTAKA Pemetaan}

Pemetaan adalah proses pengukuran, perhitungan dan penggambaran permukaan bumi (terminologi geodesi) dengan menggunakan cara dan atau metode tertentu, sehingga didapatkan hasil berupa softcopy atau hardcopy peta yang berbentuk vektor dan raster. Proses pemetaan dilakukan mulai dari pengumpulan data, pemrosesan data pembuatan petanya dan sampai ke produksinya, sehingga peta yang dihasilkan menjadi peta fisik atau benarbenar ada wujudnya.

Dalam proses pemetaan harus melalui beberapa tahapan mulai dari penyusunan ide hingga peta siap digunakan. Kesemua itu harus dilakukan dengan penuh hati-hati dan ketelitian agar diperoleh peta yang baik dan benar sera memiliki dilai artistik atau seni sehingga pengguna mampu menggunakan peta dengan maksimal dan pembuat dapat menghasilkan peta yang baik sehingga terjadi timbal balik antar pengguna dengan pembuat peta (Gunawan, 2013).

\section{Akuifer (Lapisan Pembawa Air Tanah)}

Akuifer sendiri berasal dari kata aqua yang berarti air dan fere yang berarti 
Journal of Informatics and Computer Science Vol. 4 No. 2 Oktober 2018

Universitas Ubudiyah Indonesia

e-ISSN : 2615-5346

mengandung. Dapat diartikan akuifer sebagai lapisan pembawa air atau lapisan permeable karena mampu mengalirkan air karena adanya pori-pori pada lapisan tersebut ataupun memang sifat dari lapisan batuan tertentu. Umumnya air ini terletak pada lapisan akuifer dengan jumlah air yang relatif besar. Jika tekanan air sangat besar, maka air akan memancar, baik melalui rekahan maupun melalui sumur artesis seperti pada Gambar 2.0. (Kodoatie, 2013).

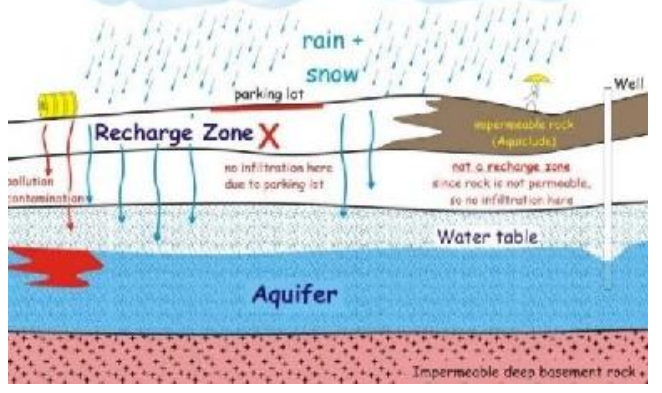

Gambar 2.1 Akuifer

\section{Geographic Information System (GIS)}

Geographic Information System (GIS) atau Sistem Informasi Geografis (SIG) adalah sebuah sistem yang di desain untuk menangkap, menyimpan, memanipulasi, menganalisa mengatur dan menampilkan seluruh jenis data geografis. Akronim GIS terkadang dipakai sebagai istilah untuk Geographical Information Science atau Geospatical Information Studies yang merupakan ilmu studi atau pekerjaan yang berhubungan dengan Geographic Information System. Dalam artian sederhana Sistem Informasi Geografis dapat kita simpulkan sebagai gabungan kartografi, analisis statistik dan teknologi sistem basis data (database) (Irwansyah, 2013:1).

\section{Geographic Information System berbasis Web (WebGIS)}

WebGIS adalah sebuah teknologi yang menggunakan website teknologi untuk memperluas dan meningkatkan GIS. Teknologi WebGIS merupakan hasil pengembangan dari aplikasi dari $G I S$, yang memungkinkan pengguna GIS untuk mengakses data spasial GIS secara online. Arsitektur WebGIS dapat digambarkan seperti pada Gambar 2.1. Arsitektur tersebut memanfaatkan Google Maps API dalam menyajikan data geospasial. Keuntungan dari arsitektur ini sederhana dan mudah dalam perawatan. Manfaat utama bagi komputasi sisi server adalah kemampuan cross platform pada sisi client. User dapat mengakses informasi yang dibutuhkan pada platform dan browser yang berbeda. Meskipun disediakan komunikasi dua arah yaitu pengguna dan penyedia informasi, sebuah dokumen yang dihasilkan tetap lambat karena ketika request diberikan, sebuah dokumen HTML yang baru, dihasilkan dan ditransfer ke client terlebih dahulu sebelum diproses ke server (Ran dan Chang, 2013).

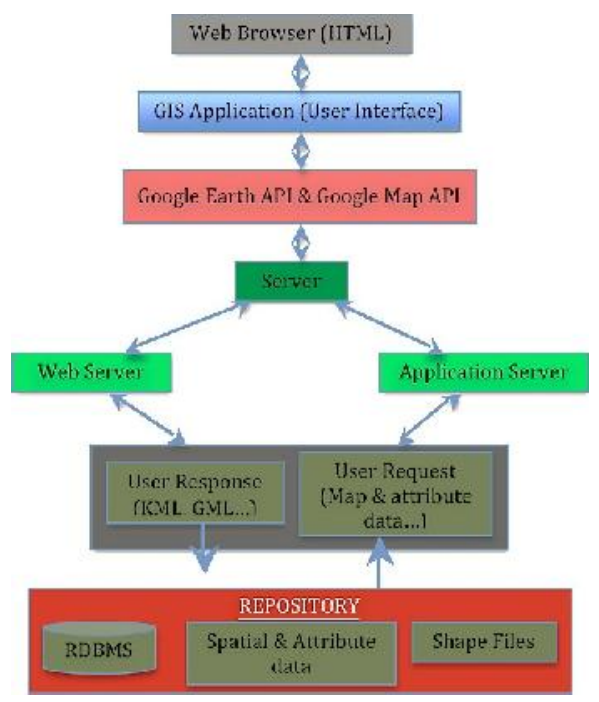

Gambar 2.2 Arsitektur dari WebGIS

\section{Entity Relationship Diagram (ERD)}

$E R D$ adalah suatu model jaringan yang menggunakan susunan data yang disimpan dari sistem acak. Digunakan untuk 
Journal of Informatics and Computer Science Vol. 4 No. 2 Oktober 2018

Universitas Ubudiyah Indonesia

e-ISSN : 2615-5346

menunjukkan objek data dan hubungan-

hubungan yang ada pada objek tersebut dengan menggunakan entity dan relationship. Selain mudah disajikan oleh perancangan database, entity relationship diagram juga menggambarkan hubungan antar entity dengan jelas beserta batasan jumlah entity dan partisipasi antar entity, serta mudah dimengerti oleh pemakai (Assafiiyah.2014).

\section{Keyhole Markup Language (KML)}

Keyhole Markup Language (KML) adalah sebuah notasi penulisan XML (Extensible Markup Language) untuk menggambarkan fitur lokasi geografis. Penggunaan file KML tidak hanya pada Google Earth saja, tetapi juga sudah terdapat beberapa program GIS, seperti ArcGIS yang mampu memproses atau mengimpor file KML (Zichar, 2012).

\section{Web}

Web adalah fasilitas internet yang menghubungkan berbagai situs pengguna secara lokal dan sedunia. Format dasar web adalah dokumen teks yang disebut sebagai halaman web (web page), yang memiliki berbagai kode HTML (Hypertext Markup Language) melekat untuk memberikan format halaman serta link ke halaman- halaman lainnya. Halaman-halaman yang terhubung tersebut dapat disimpan kedalam server. Kodekode HTML adalah karakter alfanumerik sederhana yang dapat diketik dengan editor teks. Kebanyakan prosesor mendukung fitur publikasi web yang memungkinkan dokumen teks dikonversikan ke format HTML (Ramadhan, 2014).

\section{Google Maps API}

Google Maps API merupakan aplikasi interface yang dapat diakses lewat javascript agar Google Maps dapat ditampilkan pada halaman web yang sedang kita bangun.
Untuk dapat mengakses Google Maps, kita harus melakukan pendaftaran API Key terlebih dahulu dengan data pendaftaran berupa nama domain web yang kita bangun, untuk versi yang sekarang tidak perlu menggunakan API Key. Banyak sekali kegunaan Google Maps untuk website yang kita buat, diantaranya dapat digunakan untuk menampilkan lokasi pemilik website (pada about us), lokasi event/kegiatan, atau dapat juga digunakan untuk aplikasi GIS berbasis web (Adi, 2016).

\section{ArcGIS}

ArcGIS adalah salah satu software yang dikembangkan oleh ESRI (Environment Science \& Research Institute) yang merupakan kompilasi fungsi-fungsi dari berbagai macam Software GIS yang berbeda, seperti GIS desktop, server dan GIS berbasi web. Software ini mulai dirilis oleh ESRI pada tahun 1998 dengan dilahirkannya ArcGIS 8.x.

\section{XАMPP}

$X A M P P$ adalah sebuah software yang berfungsi untuk menjalankan website berbasis PHP dan menggunakan pengolahan data $M y S Q L$ di komputer lokal. $X A M P P$ berperan sebagai server web pada komputer anda. XAMPP juga dapat disebut sebuah CPanel server virtual, yang dapat membantu melakukan preview sehingga dapat memodifikasi website tanpa harus online atau terakses dengan internet (Wicaksono, 2015).

\section{METODOLOGI PENELITIAN Jenis Penelitian}

Penelitian ini menggunakan jenis penelitian kuantitatif yaitu menggunakan data yang telah didapatkan dari Dinas Pertambangan dan 
Journal of Informatics and Computer Science Vol. 4 No. 2 Oktober 2018

Universitas Ubudiyah Indonesia

e-ISSN : 2615-5346

Energi Aceh dengan tujuan untuk merancang Sistem Informasi Geografis Pemetaan Letak Akuifer, sehingga data yang terangkum merupakan informasi- informasi yang saling berkaitan satu sama lain serta beralasan sesuai dengan keadaan yang sebenarnya.

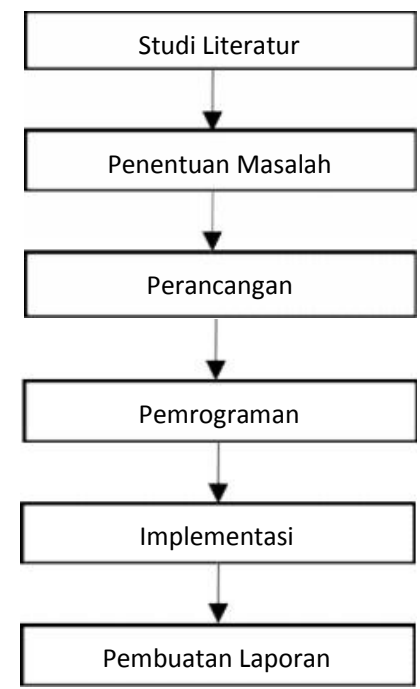

Gambar 3.1 Alur Penelitian

Alat dan bahan yang digunakan dalam pembuatan sistem informasi ini adalah sebagai berikut:

1. Perangkat keras

1 Unit Komputer dengan spesifikasi cukup untuk menjalankan aplikasi Arc GIS dan XAMPP.

2. Perangkat lunak

a. Arc GIS, untuk mengolah data spasial.

b. XAMPP, sebagai web server yang terdiri dari Apache HTTP Server, MySQL database dan dengan bahasa pemrograman PHP dan Perl.

c. Notepad++, sebagai Text Editor yang digunakan untuk menulis kode program.

\section{HASIL}

\section{Hasil Pengujian Aplikasi}

Hasil dari penelitian ini adalah menghasilkan aplikasi yang dapat menampilkan data lokasi sumur bor pada Provinsi Aceh, yang dapat diakses oleh admin maupun user. Masyarakat mampu menemukan lokasi sumur bor berdasarkan letak akuifer yang sesuai dengan pertimbangan berdasarkan informasi yang disediakan.

\subsection{Hasil Ujicoba Aplikasi}

Pada halaman utama aplikasi ini terdapat Menu Beranda, Peta, Kontak, Data Sumur Bor, dan Login. Halaman utama merupakan halaman awal dari sistem informasi geografis pemetaan letak akuifer yang dapat di akses secara umum yang menampilkan informasi singkat tentang sumur bor, halaman ini dapat diakses oleh admin dan user umum.

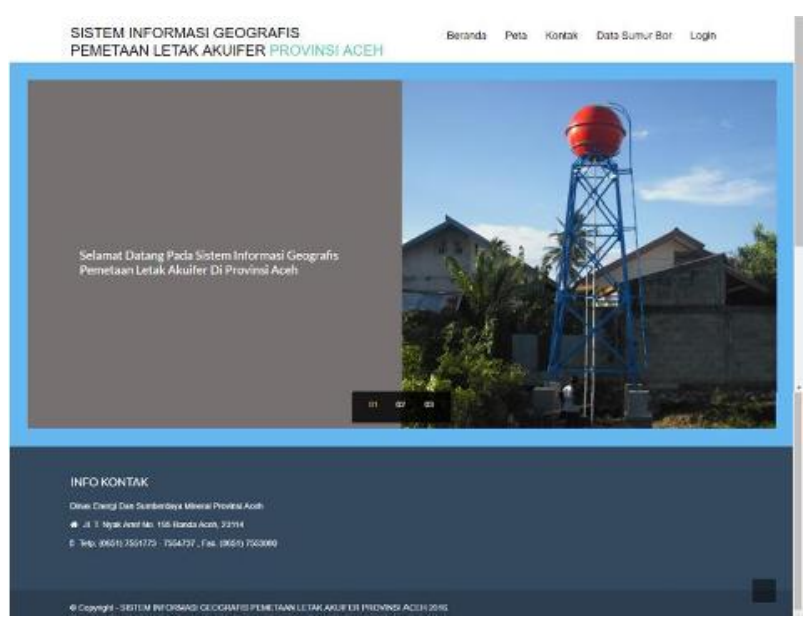

Gambar 4.1 Halaman Utama

Pada menu Peta, menampilkan peta ke dalam web merupakan tujuan utama dari pembuatan web GIS. Terdapat simbol marker yang merupakan titik lokasi sumur bor di Provinsi Aceh dan tampilan checkbox yang membantu dalam proses menampilkan 
Journal of Informatics and Computer Science Vol. 4 No. 2 Oktober 2018

Universitas Ubudiyah Indonesia

e-ISSN : 2615-5346

peta

sesuai dengan tujuan dan fasilitas fitur yang telah disediakan, juga menampilkan layer ke dalam peta. Menu Peta ini terdapat 1 menu drop down untuk mengetahui jumlah sumur bor di setiap Kabupaten/Kota dan 3 bagian menu checkbox yaitu Batas Kabupaten, Arah Aliran Air Tanah dan Peta Cekungan Air Tanah.

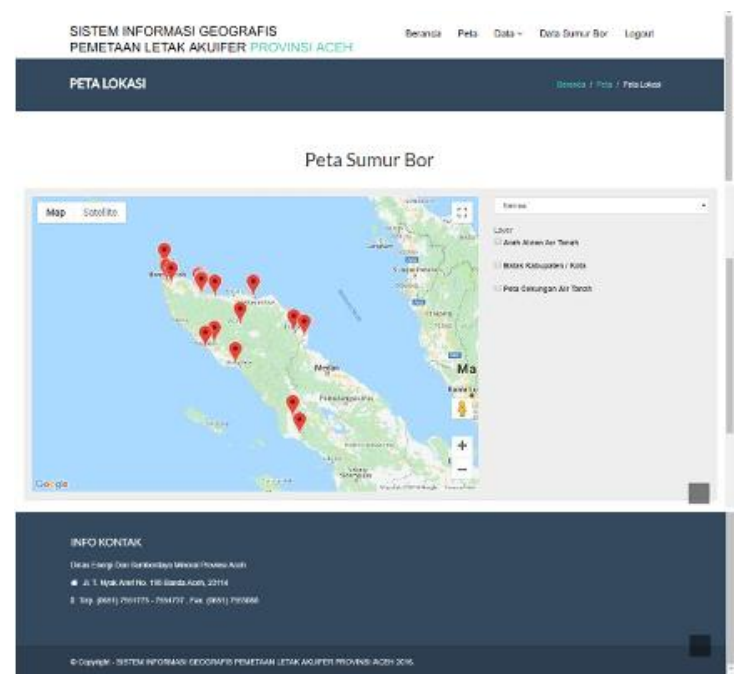

Gambar 4.2 Halaman Menu Peta

Pada halaman Peta terdapat menu drop down yang berfungsi untuk menampilkan lokasi sumur bor berdasarkan Kabupaten/Kota yang terdapat di Provinsi Aceh. Sehingga dapat diketahui berapa jumlah sumur bor di setiap Kabupaten/Kota dan juga memudahkan user dalam melakukan pencarian data sumur bor.

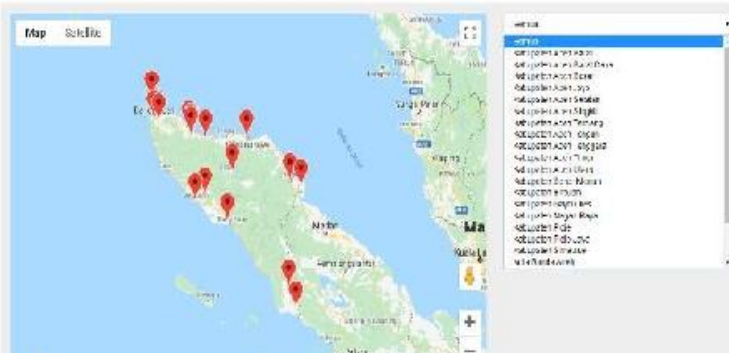

Gambar 4.3 Menu Drop Down Peta Pada

simbol marker terdapat informasi

detail mengenai lokasi sumur bor yang berisi foto sumur bor, lokasi sumur bor serta dapat mengetahui kedalaman akuifer pada sumur bor.

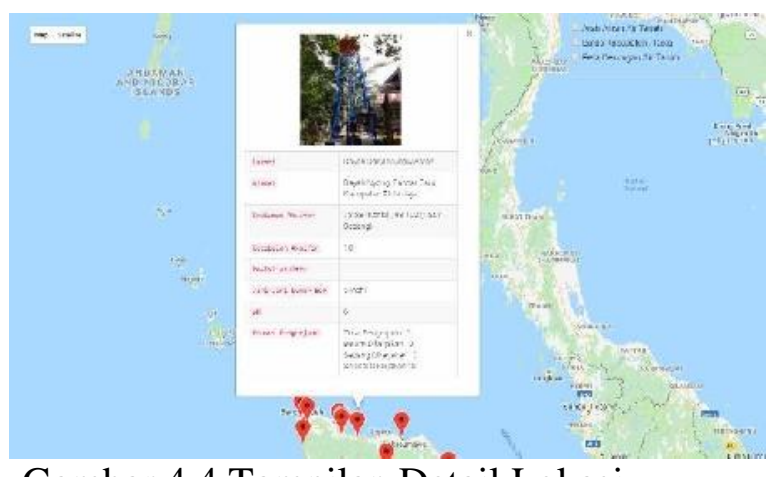

Gambar 4.4 Tampilan Detail Lokasi

Sumur Bor

Tampilan batas Kabupaten/Kota ini berfungsi untuk mengetahui letak lokasi sumur bor di setiap Kabupaten/Kota yang terdapat di Provinsi Aceh dengan legenda sebagai penjelasan dari layer.

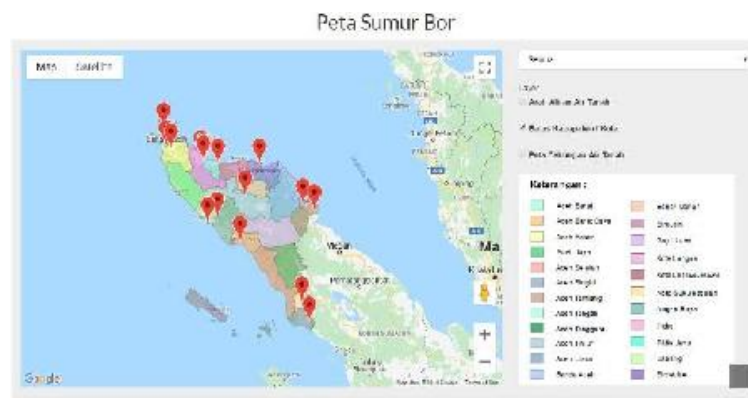

Gambar 4.5 Tampilan Batas Kabupaten / Kota Provinsi Aceh

Arah aliran air tanah pada aplikasi ini berfungsi untuk mengetahui pergerakan aliran air tanah yang menjadi kunci dalam menentukan apakah suatu daerah mengandung banyak air tanah atau tidak pada suatu wilayah. 
Journal of Informatics and Computer Science Vol. 4 No. 2 Oktober 2018

Universitas Ubudiyah Indonesia

e-ISSN : 2615-5346

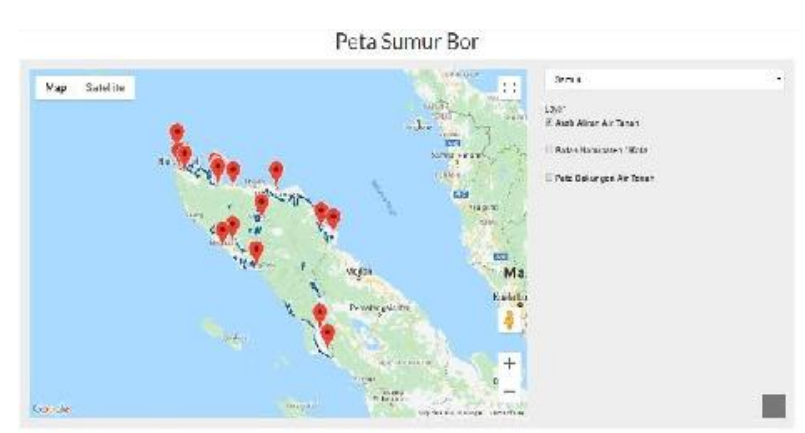

Gambar 4.6 Tampilan Arah Aliran Air Tanah

Peta cekungan air tanah pada aplikasi ini berfungsi sebagai acuan dalam pembuatan sumur bor di lokasi-lokasi yang berpotensi mengandung air tanah. Jika di klik pada menu checkbox peta cekungan air tanah ini maka, akan muncul peta dengan cekungan air tanah yang ada di Provinsi Aceh.

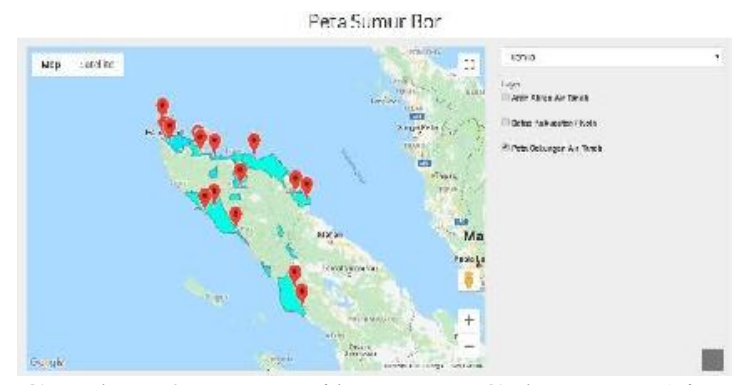

Gambar 4.7 Tampilan Peta Cekungan Air Tanah

\section{KESIMPULAN DAN SARAN}

Kesimpulan dari perancangan sistem informasi geografis pemetaan letak akuifer Provinsi Aceh adalah sebagai berikut:

1. Aplikasi dapat membantu petugas atau masyarakat untuk mengetahui letak akuifer dan informasi mengenai sumur bor pada setiap Kabupaten/Kota di Provinsi Aceh yang ditampilkan dalam bentuk peta online.

2. Petugas atau masyarakat dapat dengan cepat mengetahui daerah mana saja yang mengandung banyak air jika dilihat dari keadaan geologi pada suatu daerah.
3. Dapat dijadikan acuan dalam pengambilan keputusan oleh Petugas atau masyarakat untuk mendukung perencaan lokasi untuk dilakukannya sumur bor yang tepat sesuai pertimbangan berdasarkan informasi yang disediakan.

Adapun saran yang diberikan dalam pembuatan dan pemanfaatan sistem perlu adanya pengembangan dimasa mendatang. Untuk penelitian selanjutnya dapat dikembangkan dengan menambah fungsi web service sehingga memudahkan user dalam penggunaanya dan informasi yang disediakan lebih banyak, serta memungkinkan terintergrasinya aplikasi ini dengan sistem pada Dinas Pertambangan dan Energi Aceh.

\section{DAFTAR PUSTAKA}

Adi, Arista Prasetyo. 2016. The Best Tools For Wordpress. Jakarta. PT Elex Media Komputindo.

Assafiiyah. 2014. Model Entity Relationship Diagram (ERD). Jakarta. Media Kita.

Azis, Farid. 2015. Object Oriented Programming dengan PHP 5. Jakarta. PT Elex Media Komputindo.

Gunawan, Totok. 2013. Fakta dan Konsep Geografis. Jakarta. Inter Plus.

Hutahaean, Jeperson. 2014. Konsep Sistem Informasi. Yogyakarta. Deepublish.

Irwansyah, Edy. 2013. Sistem Informasi Geografis: Prinsip Dasar dan Pengembangan Aplikasi. Yogyakarta. Digibooks.

Kodoatie, Robert J. and Roestam Syarief. 2013. Tata Ruang Air. C.V Andi Offset.

Kurniawan, Dedik. 2013. 145 Freeware Pilihan Untuk Berbagi Kebutuhan. Jakarta. PT Elex Media Komputindo.

Madcoms, Madiun. 2014. Teknik Mudah Membangun Website dengan HTML, 
Journal of Informatics and Computer Science Vol. 4 No. 2 Oktober 2018

Universitas Ubudiyah Indonesia

e-ISSN : 2615-5346

PHP, dan MYSQL. Surabaya.

Muslihuddin. 2016. Wikipedia Apoteker. Jakarta. PT Guepedia.

Nirwansyah, Anang Widhi. 2017. Dasar Sistem Informasi Geografis dan Aplikasinya Menggunakan Arc GIS

9.3. Yogyakarta. Deepublish. Ramadhan, Arief. 2014. Student Guide Series

Pemrograman Web. Jakarta. PT Elex Media Komputindo.

Ran, B. and B.P. Chang. 2013. Architecture Development for Web-Based GIS, Application in Transportation. Transportation Research Board Annual Meeting.
Setiabudi, D.H. 2015. Aplikasi Ecommerce www.komputeronline.com Dengan Menggunakan MySQL dan PHP4. Jurnal Informatika Vol.3, No.2, November 2015.

Wicaksono, Yogi. 2015. Membangun Bisnis Online dengan Mambo. Jakarta. PT Elex Media Komputindo.

Zichar, M. 2012. Geovisualization based upon KML. Journal of Agricultural Informatics.

Hongaria

http://journal.magisz.org. 
